\title{
Research and Application of Web3D Exhibition Based on WebGL and Html5
}

\author{
M.J. Bian \\ School of Computer Engineering and Science \\ Shanghai University \\ Shanghai, China
}

J. Gao

Computer Center

Shanghai University

Shanghai, China

\begin{abstract}
With the development of compute technology and Internet, most applications of our daily life and work depend on the Internet. People began to take more and more attention on the $3 D$ visualization in these web applications, which can provide a better user experience. Therefore, Web3D, composed of 3D technology and Internet technology, has become a new research hotspot. In the paper, we designed a solution of Web3D exhibition by combining WebGL and Html5. We developed a Web3D exhibition building system (Web3D-EBS) to build Web3D exhibitions in web applications, which has good compatibility and runs depending on the GPU without any plug-in. Web3D-EBS is applied to the project of Digital Museums of Colleges and Universities in Shanghai, which proved the solution has good convenience and effectiveness in Web3D exhibition applications.
\end{abstract}

Keywords- Web3D; virtual reality; WebGL; Html5; digital museum

\section{INTRODUCTION}

\section{A. Web3D Current Situation}

Web3D technology can be traced back to the VRML (Virtual Reality Modeling Language). In 1998, VRML Association completed the conversion from VRML to Extensible 3D (Extensible 3D Language) and was renamed Web3D Consortium. It was the first time that the word Web3D being used [1]. Many famous organizations have launched their own the web3D technologies, such as Cycore's Cult3D, Sun Microsystems's Java3D and so on. However, Web3D still have many problems, such as low rendering efficiency, poor compatibility, need to plug-in and so on. Each Web3D technology has its own characteristics and advantages, the competition will exist for a long time.

\section{B. Web3D Solutions}

Now, there are many Web3D solutions, such as, Java3D, Flash3D, VRML, Cult3D and so on. They have their own advantages and disadvantages.

1) Java3D. Java3D can deal with complex $3 D$ applications and has good compatibility among these browsers which support JVM (Java Virtual Machine). However, the disadvantage of Java3D is that most operating systems such as

\author{
H.H. Gao \\ Computer Center \\ Shanghai University \\ Shanghai, China
}

\author{
J.P. Xu \\ Shang Da Hai Run Information System.Co. Ltd, \\ Shanghai, China
}

Windows, do not default install with JVM which limits the use of Java3D.

2) $X 3 D / V R M L$. X3D/VRML 2.0(VRML97) has a simple operation like JavaScript. However, when Intel set up the Web3D group to unify the Web3D standard, no discussion of X3D was mentioned, which means that it is not clear whether X3D can become an international standard [2].

3) Cult3D. Cult3D can be integrated with high-level language such as Java to enhance the interactivity and extensibility of Web3D applications and the IDE (Integrated Development Environment) has good efficiency. However, most of browsers do not default install Cult3D plug-in and the Web3D application with Cult3D needs high quality 3D model which means low compatibility and high development cost are the main problems of Cult3D[3].

In brief, the disadvantages of most existing Web3D solutions are low development efficiency, low compatibility, not directly supporting GPU, needing plug-in. Therefore, the main purpose of the paper is to find a Web3D solution to solve these problems as far as possible.

\section{KEY TECHNOLOGY}

In order to solve the problems mentioned above, we design a Web3D solution based on WebGL and HTML 5 in the paper.

\section{A. WebGL}

WebGL is a 3D graphics standard designed by Khronos Group. WebGL is a set of open source Web browser 3D graphics APIs created by Mozilla [4] [5]. The traditional Web3D solutions always need plug-ins in browser to render 3D graphics, such as Java3D and Direct3D. Another disadvantage of these solutions is that they don't make effective use of GPU to render 3D graphics so that it is difficult to efficiently render a complex 3D scene in browser. WebGL can solve the problem, because it is based on OpenGL ES 2.0 standard and OpenGL and can provide OpenGL APIs as well. 


\section{B. Html5}

Html5 was once known as Web Applications 1.0 proposed by WHATWG (Web Hypertext Application Technology Working Group) in 2004. In 2007, W3C (World Wide Web Consortium) established the new Html working group [6]. In web applications, Html5 provides supports for 3D graphics, such as SVG (Scalable Vector Graphics), Canvas, WebGL. On the other hand, another goal of $\mathrm{Html} 5$ is to create a seamless and unified network [7]. Therefore, Html5 can provide Web3D with very good compatibility.

\section{Threejs}

In order to increase the efficiency and flexibility of building Web3D exhibition, we refer Threejs to the Web3D solution designed in the paper. Threejs is open source and built based on WebGL using JavaScript. WebGL is very complicated to use, which will make the development low efficient and high-cost. Using Theejs can solve the problem [8]. Threejs encapsulates most 3D graphics processing functions of WebGL by JavaScript and provides lots of 3D graphics objects used to establish a 3D scene in browser, such as camera, light, model, the schematic diagram as Figure 1.

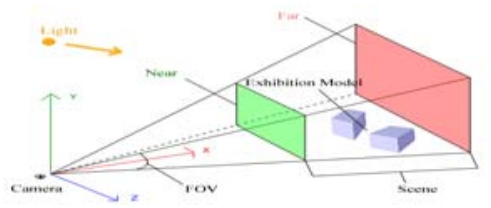

FIGURE I : SCHEMATIC DIAGRAM OF ESTABLISHING 3D SCENE.

\section{DESIGN OF THE WEB3D EXHIBITION BUILDING SYSTEM}

In the paper, we design a Web3D exhibition building system (Web3D-EBS) as a Web3D solution based on WebGL and Html5. The structure of Web3D-EBS is shown in Figure 2.

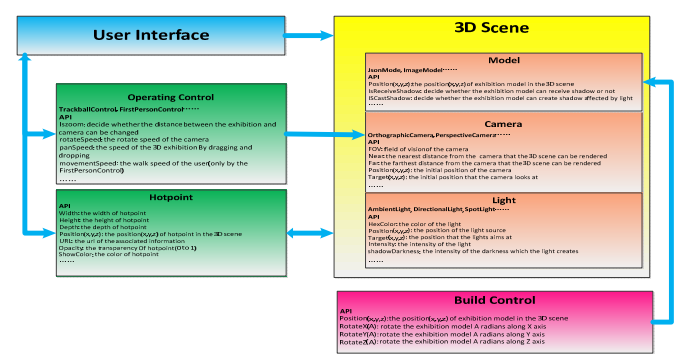

FIGURE II : STRUCTURE OF WEB3D-EBS.

\section{A. Camera}

Camera is used to observe the Web3D exhibitions in browser. Different camera has different effect, such as Orthogonal Camera and Perspective Camera. Perspective Camera has the effect imitating human eyes and usually applied to observe Web3D exhibitions and virtual roaming.

\section{B. Operating Control}

Operating Control is used to determine the operating mode of the user. Trackball Control can keep the Web3D exhibition in a fixed position. User can change the camera position to observe the exhibitions by operating mouse. First Person
Control imitate human walking in the 3D scene by operating mouse and keyboard.

\section{Light}

Light can affect the rendering effect of the 3D scene in browser. There are several types of light objects to be used in Threejs, such as Ambient Light, Directional Light and Spot Light.

\section{Model}

Model is used to transform physical exhibitions to Web3D exhibitions so that users can observe and operate the exhibitions in browser. Model is processed by GPU and rendered by browser. WebGL supports several kinds of model, such as Image Model, Json Model. Image Model can be compatible with the traditional C/S model, such as the model from 3DMax, Unity3D.

\section{E. Hotpoint}

We designed an interaction object called as Hotpoint in the paper. In Web3D application, the 3D space point can be mapped to the Hotpoint like a 2D space point in browser. So, user can locate and operate any point in 3D scene by operating mouse and keyboard. For example, we can click one small part of the Web3D exhibition to get more detail information.

\section{F. Build Control}

To provide more convenient for the designer of the Web3D application when building Web3D exhibitions, we designed Build Control to assist Web3D exhibition building based Ajax and Threejs. Designer can adjust the position and angle of the 3D exhibition in real time until generating the final version of the Web3D exhibition.

\section{THE EXAMPLE FOR APPLICATION}

Today, the main study and application of Web3D is focus on virtual reality development. Many museums have established their digital museums through 3D virtual roaming technology. In the paper, we applied the Web3D solution to the project of Digital Museums of Colleges and Universities in Shanghai and developed the Web3D-EBS to building the Web3D exhibitions in the digital museums [9]. Designers can build Web3D exhibitions and adjust the position and angle. In Figure 3, we adjust the color, position and intensity of the Spot Light with the help of Build Control. When the final version of the Web3D exhibitions published in the digital museums, users can observe them from different distance and at different angle, as shown in Figure 4.

The Hotpoint we developed in Web3D-EBS provides users better interactivity. We can add a Hotpoint into a 3D scene and set the property, such as location, color, transparency and the information associated with, as shown in Figure 5. For example, when clicking the red Hotpoint beside the Web3D exhibition, the associated detail information will be shown in browser, as shown in Figure 6. 


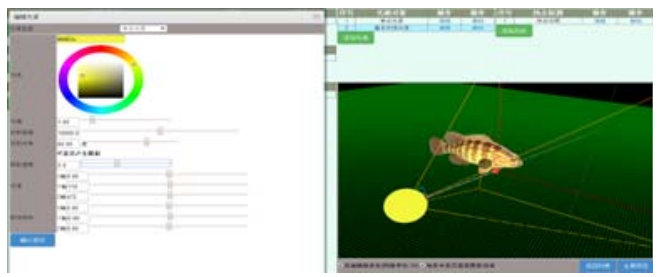

FIGURE III: OPERATION INTERFACE OF WEB3D-EBS.
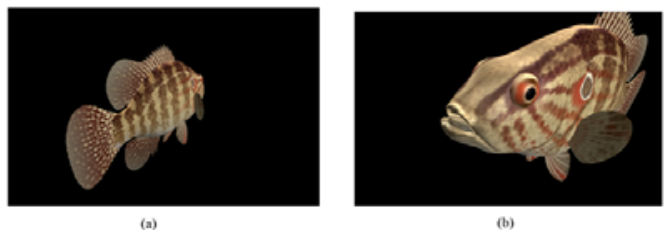

FIGURE IV. (A) OBSERVE ON THE BACK, (B) OBSERVE IN A CLOSER DISTANCE.

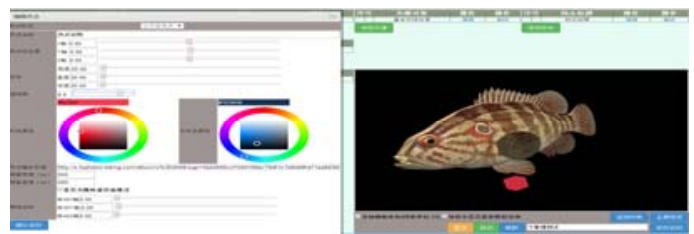

FIGURE V : OPERATION INTERFACE OF SETTING HOTPOINT.
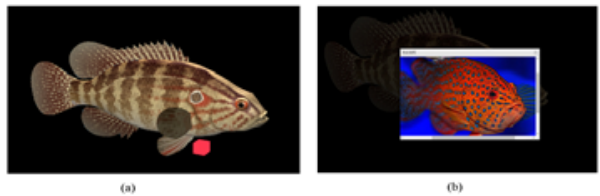

FIGURE VI: (A) HOTPOINT BESIDE WEB3D EXHIBITION, (B) SHOW MORE INFORMATION.

\section{V.CONCLUSION}

In the paper, we designed a Web3D solution by combining with WebGL and Html5. We developed a Web3D exhibition building system (Web3D-EBS). We applied the Web3D-EBS to build Web3D exhibitions in the project of Digital Museums of Colleges and Universities in Shanghai. These Web3D exhibitions can be rendered in browser directly through GPU without any plug-in and provide users with more interaction by Hotpoint, which proved that the solution designed in the paper make Web3D exhibition building more convenient, compatible and efficient.

\section{ACKNOWLEDGEMENT}

This work was supported by National Science and Technology Major Project of the Ministry of Science and Technology of China under Grant No.2011ZX04003-022. I'd like to express my sincere thanks to all those who have lent me hands in the course of my writing this paper. First of all, I'd like to take this opportunity to show my sincere gratitude to my supervisor, Prof. $\mathrm{Xu} \mathrm{HuaHu,} \mathrm{who} \mathrm{has} \mathrm{given} \mathrm{me} \mathrm{so}$ much useful advices on my writing, and has tried his best to improve my paper. Secondly, I'd like to express my gratitude to my colleague, Dr. Gao HongHao who offered me references and information on time. Without their help, it would be much harder for me to finish my study and this paper.

\section{REFERENCES}

[1] Khronos Group. Web3D, Virtual Reality Modeling Language. International Standard[S] ISO/IEC 14772-1:1997.

[2] Ming W. A 3D WebGIS system based on VRML and X3D [C]. Genetic and Evolutionay Computing, 2008. WGEC'08 Second International Conference on. IEEE, 2008:197-200.

[3] Guan T, Ren BY, Zhong DH. The method of Unity3D based 3D dynamic interactive query of high arch dam construction information [J]. Applied Mechanics and Materials, 2013, 256(1): 2918-2922.

[4] Diego Cantor, Brandon Jones. WebGL Beginner's Guide, Packt Publishing, 2012-6-15

[5] Parisi T. WebGL: up and running [M]. Sebastopol: O’Reilly Media, Incorporated, 2012.

[6] Vaughan-Nichols S J. Will HTML5 restandardize the web? [J]. Computer, 2010, 43(4):13-15.

[7] Lubbem P, Salim F, Albers B. Pro HTML5 programming [M]. press 2011.

[8] Dollner J, Hinrichs K. An object-oriented approach for integrating 3D visualization systems and GIS [J]. Computers\& Geosciences, 2000, 26(1):67-76.

[9] Si Z, Li S Y, Huang L z, et al. Visualization programming for batch processing of contour maps based on VB and surfer software [J]. Advances in Engineering Software, 2010, 41(7):962-96. 